\title{
Representation of Grammatical Categories of Words in the Brain
}

\section{Citation}

Hillis, Argye E., and Alfonso Caramazza. 1995. Representation of grammatical categories of words in the brain. Journal of Cognitive Neuroscience 7(3): 396-407.

\section{Published Version}

doi:10.1162/jocn.1995.7.3.396

\section{Permanent link}

http://nrs.harvard.edu/urn-3:HUL.InstRepos:3626280

\section{Terms of Use}

This article was downloaded from Harvard University's DASH repository, and is made available under the terms and conditions applicable to Other Posted Material, as set forth at http:// nrs.harvard.edu/urn-3:HUL.InstRepos:dash.current.terms-of-use\#LAA

\section{Share Your Story}

The Harvard community has made this article openly available.

Please share how this access benefits you. Submit a story.

Accessibility 


\title{
Representation of Grammatical Categories of Words in the Brain
}

\author{
Argye E. Hillis \\ Johns Hopkins University \\ Alfonso Caramazza \\ Dartmouth College
}

\begin{abstract}
We report the performance of a patient who, as a consequence of left frontal and temporoparietal strokes, makes far more errors on nouns than on verbs in spoken output tasks, but makes far more errors on verbs than on nouns in written input tasks. This double dissociation within a single patient with respect to grammatical category provides evidence for the hypothesis that phonological and orthographic representations of nouns and verbs are processed by independent neural mechanisms. Furthermore, the opposite dissociation in the ver-
\end{abstract}

\section{INTRODUCTION}

Knowledge of the meaning and of the phonological and orthographic forms of words is represented independently in the brain as evidenced by the fact that each of these forms of word knowledge can be selectively impaired as the result of brain damage (Ellis, Miller, \& Sin, 1983; Hillis, Rapp, Romani, \& Caramazza, 1990; Patterson \& Morton, 1985; Roeltgen, Rothi, \& Heilman, 1986; see also Caramazza, 1988 and Ellis \& Young, 1988, for review). In addition, there is evidence from the analysis of the performance of brain-damaged subjects for finergrained distinctions in the representation of knowledge within the semantic, the phonological, and the orthographic lexical components (Goodglass, Klein, Carey, \& Jones, 1966; Warrington, 1981). Thus, there are reports of semantic category-specific deficits, the most prevalent being the selective damage of the "living things" category (Basso, Capitani, \& Laiacona, 1988; Farah, Hammond, Metha, \& Ratcliff, 1989; Hart, Berndt, \& Caramazza, 1985; Hart \& Gordon, 1993; McCarthy \& Warrington, 1989; Nielson, 1936; Sartori \& Job, 1988; Silveri \& Gainotti, 1988; Tranel, Damasio, \& Damasio, 1988, Warrington \& McCarthy, 1987; Warrington \& Shallice, 1984). For example, circumscribed brain lesions can affect the ability to retrieve the meaning of animal names, but not names of artifacts, or can have the reverse effect (Hillis \& Caramazza, 1991). These patterns of performance suggest

bal output modality, an advantage for nouns over verbs in spoken tasks, by a different patient using the same stimuli has also been reported (Caramazza \& Hillis, 1991). This doublc dissociation across patients on the same task indicates that results cannot be ascribed to "greater difficulty" with one type of stimulus, and provides further evidence for the view that grammatical category information is an important organizational principle of lexical knowledge in the brain.

that either the representations of meanings are processed by discrete brain mechanisms for different semantic categories of words, or that certain aspects of meaning that pertain to some categories more than others (either sensory features, such as color or shape information, or semantic features, such as "edible" or "breathes") are processed by separate mechanisms or in separate brain regions (Caramazza, Hillis, Leek, \& Miozzo. 1994; Damasio, 1990; Warrington \& McCarthy, 1983).

Other studies have shown that brain damage can also selectively affect specific grammatical categories of words, such as nouns versus verbs (Baxter $\&$ Warrington, 1985; McCarthy \& Warrington, 1985; Miceli, Silveri, Nocentini, \& Caramazza, 1988; Miceli, Silveri, Villa, \& Caramazza, 1984; Zingeser \& Berndt, 1988). Furthermore, it has been reported that such a selective deficit in processing of a single grammatical category (verbs) can be restricted to a single modality of output (Caramazza \& Hillis, 1991). Evidence for the latter conclusion is based on performance by two neurologically impaired patients, HW and SJD, who showed complementary deficits with respect to spoken versus written output. HW showed a greater impairment for verbs than nouns in naming and oral reading but not in writing; SIJ) showed the same dissociation between nouns and verbs, but in written naming and spelling-to-dictation and not in speech (Caramazza \& Hillis, 1991).

The results from HW and SJD were interpreted as 
indicating that there are separate brain mechanisms devoted to the retrieval of pronunciations and the spellings of words, and that grammatical category information is represented independently and redundantly in these two lexical components. However, the strength of this conclusion is compromised by the fact that the impairment was selective for nouns in both cases. Alternative explanations for the observed patterns of performance include (1) verbs are more difficult to process than nouns, so that a deficit in retrieving words for spoken or written output would differentially affect the verbs, and (2) verbs are more closely linked to grammatical processing, so that damage to connections between grammatical processing and spoken or written vocabulary would differentially affect the verbs (see Hooper, 1991, for review of these criticisms). In this paper we report the opposite dissociation-greater impairment of nouns relative to verbs in spoken output by a patient, EBAwhich is not subject to these alternative accounts. Thus, these data, together with those in previously reported studies, converge in support of the hypothesis that lexical representations of separate categories of words are processed by separate neural mechanisms. If this hypothesis is correct, it should be possible to find patients who show both a deficit in processing words of one grammatical class in one modality and a deficit in processing words of another grammatical class in the other modality. The patient we report here, EBA, shows this double dissociation. These results provide compelling evidence for the hypothesis that lexical knowledge is organized in the brain such that representations of different grammatical categories of words are processed by different brain structures or mechanisms.

\section{RESULTS}

To obtain evidence in support of the hypothesis that lexical representations (for output) are organized by the grammatical categories of words, the first experiment was designed to document that the subject (EBA) had a deficit, like that of HW and SJD reported in Caramazza and Hillis (1991), which was specific to spoken and/or written output, and not a reflection of an underlying semantic impairment. Toward this goal, performance of EBA-a dextral woman, with a history of left hemisphere strokes (the most recent being 2 years before testing) that resulted in anomic aphasia and severe dyslexiawas compared across production and comprehension tasks. Additional experiments were then undertaken to analyze performance on nouns versus verbs, with emphasis on (1) the contrast between EBA's pattern of performance and HW's pattern of performance, which demonstrates the presence of a double dissociation between grammatical word classes within the spoken modality, and (2) the contrast between EBA's processing of lexical representations of a given word class for spoken output versus written input, which demonstrates a dou- ble dissociation between modalities in accessing lexical representations of nouns and verbs.

\section{Performance across Tasks: Naming vs. Comprehension}

To identify the modalities of input and output that were affected by the patient's brain damage, a set of black and white pictures was presented for oral naming, oral reading, and word/picture matching, in separate sessions. The pictures for these tasks were a set of 260 black and white pictures of objects, for which there are published data for name agreement, familiarity, visual complexity, and word frequency (Snodgrass \& Vanderwart, 1980). In each session, tasks of oral naming, oral reading, and auditory word comprehension were presented in blocks using different subsets of the items. The order of the tasks was systematically varied, such that the three tasks were each presented in each position of the sequence an equal number of times, and the number of items that were presented first for naming was equal to the number of items presented first for reading or first for comprehension. For the word/picture verification tasks, each spoken name was presented three times on separate occasions, once with the correct picture, once with a semantically related picture from the same set of 260 , and once with a semantically unrelated picture from the set. For the last foil type an effort was made to use pictures with names that are phonologically and/or visually similar to the stimulus word (e.g., HAIR/"chair"). ${ }^{1}$ In each session one-third of the words were presented with each of the foil types, in random order. EBA was asked to verify or reject the correspondence between the picture and a spoken word. An item was scored as correct if, in response to the word, she accepted the correct picture and correctly rejected both the related and the unrelated pictures as referents of the word across the three trials.

EBA correctly named only $11 \%(28 / 260)$ of the pictures and correctly read only $13 \%$ (35/260) of the corresponding names, including self-corrections on both tasks (e.g., a pictured clothes pin was named as "clothes hamper . . . no, box, ... I mean clothes pin"; and the word cat was read as "bug ... dog . . cat!"). There was not a significant difference in her accuracy levels on the two verbal output tasks $\left(\chi_{1}^{2}=0.88\right.$; ns). Except for some omissions in reading but not in picture naming, her errors in the two tasks were indistinguishable, and could be broadly classified as "semantic errors" (e.g., camel $\rightarrow$ "elephant"; pipe $\rightarrow$ "for smoking"; PIPE $\rightarrow$ "smoke"). ${ }^{2}$ The distribution and examples of various types of errors are shown in Tables 1 and 2.

EBA's comprehension of the printed and spoken words was good: she made only one error on a task in which she was to verify or reject the correspondence between the picture and a spoken word, when each of the 260 pictures was presented, on separate occasions, 
Table 1. EBA's Performance on Oral Reading of Object Names

\begin{tabular}{lcc}
\hline & $\begin{array}{c}\text { Number of Responses } \\
\text { (\% of 260 total) }\end{array}$ & Examples \\
\hline $\begin{array}{l}\text { Correct reponses } \\
\text { Errors } \\
\text { Coordinate semantic crrors }\end{array}$ & $34(13)$ & bair $\rightarrow$ "hair" \\
Superordinate semantic errors & $10(4)$ & $\begin{array}{c}\text { blouse } \rightarrow \text { "dress"; fox } \rightarrow \text { "cat"; arm } \rightarrow \text { "head"; accordian } \rightarrow \\
\text { "trumpet" } \\
\text { donkey } \rightarrow \text { "animal"; eagle } \rightarrow \text { "bird"; pliers } \rightarrow \text { "tool"; gorilla } \rightarrow \\
\text { "big animal" } \\
\text { sled } \rightarrow \text { "sking"; harp } \rightarrow \text { "music"; ironing board } \rightarrow \text { "wash"; } \\
\text { wagon } \rightarrow \text { "traveling" }\end{array}$ \\
$\begin{array}{l}\text { Descriptions } \\
\text { paintbrush } \rightarrow \text { "something you use when you're painting"; } \\
\text { scissors } \rightarrow \text { "use for sewing, to cut something" } \\
\text { barn } \rightarrow \text { "I don't know" }\end{array}$ \\
\hline
\end{tabular}

Table 2. EBA's Performance on Naming and Comprehension of Object Names

\begin{tabular}{|c|c|c|}
\hline & $\begin{array}{l}\text { Number of Responses } \\
\text { (\% of } 260 \text { total) }\end{array}$ & Examples \\
\hline \multicolumn{3}{|l|}{ Oral naming } \\
\hline Correct reponses & $28(11)$ & HAIR $\rightarrow$ "hair" \\
\hline \multicolumn{3}{|l|}{ Errors } \\
\hline Coordinate semantic errors & $73(28)$ & $\begin{array}{l}\text { BLOUSE } \rightarrow \text { "shorts"; FOX } \rightarrow \text { "rabbit"; LEOPARD } \rightarrow \text { "peacock"; } \\
\text { BELT } \rightarrow \text { "shoes" }\end{array}$ \\
\hline Superordinate semantic errors & $8(3)$ & $\begin{array}{l}\text { DUCK } \rightarrow \text { “animal"; GRAPES } \rightarrow \text { "fruit"; CAP } \rightarrow \text { "men's wear"; } \\
\text { CHICKEN } \rightarrow \text { "bird" }\end{array}$ \\
\hline Associative semantic errors & $18(7)$ & IRON $\rightarrow$ "wash"; PIPE $\rightarrow$ "smoke"; BOOK $\rightarrow$ "read"; CANDLE $\rightarrow$ "light" \\
\hline Descriptions & $133(51)$ & $\begin{array}{l}\text { PAINTBRUSH } \rightarrow \text { "used when you're painting"; TAPE } \rightarrow \text { "I use it when } \\
\text { l'm wrapping stuff, a wrapper." }\end{array}$ \\
\hline Omissions/"don't know" & 0 & \\
\hline $\begin{array}{l}\text { Visually/phonologically } \\
\text { similar word }\end{array}$ & 0 & \\
\hline \multicolumn{3}{|c|}{ Comprehension (spoken word/picture verification) } \\
\hline Correct responses & $259(>99)$ & \\
\hline \multicolumn{3}{|l|}{ Errors } \\
\hline Coordinate semantic errors & $1(<1)$ & Accepted a picture of a skirt as a match for the word "dress" \\
\hline $\begin{array}{l}\text { Visually/phonologically } \\
\text { sinilar word }\end{array}$ & 0 & \\
\hline
\end{tabular}

with the correct word, a semantically related word, or a semantically unrelated word. Using printed word stimuli in the same task, she made only five errors on the 780 trials. ${ }^{3}$

\section{Comment}

EBA's performance in various naming and oral reading tasks revealed a striking dissociation between her ability to process the meaning (spared) and her ability to re- trieve the phonological form of words (impaired). In simple naming and reading tasks she correctly named only $10-15 \%$ of the stimuli. Oral reading and oral naming of objects were very similar both in accuracy and in the quality of her errors. Although all of her errors in both tasks were semantically related to the target response, the underlying cause for these errors is unlikely to be damage to the semantic component of lexical processing since EBA performed virtually flawlessly in word comprehension tasks (see Table 2 ). That is, in contrast to her 
severely impaired spoken output, her performance in spoken word/picture matching was quite accurate (equal to age-matched, normal controls), indicating that her processing of spoken words and pictures is unimpaired through the level of comprehension. Additional support for this conclusion is provided by her reading responses, which indicate that she understands object names that she cannot read aloud. For instance, she read pineapple as "from Hawaii, you can eat it without cooking it; it's sweet." In addition to intact semantic processing, she also showed intact motor planning and articulation of complex phonemic sequences (e.g., her production of verbal responses in oral reading and oral naming was fluent with no phonemic errors, and repetition of multisyllabic pseudowords, as well as words, was normal). Thus, her errors in oral naming and reading can be explained only by proposing an impairment in naming after adequately retrieving the semantics of the item (a stored representation of its meaning), but before articulating a response. ${ }^{4}$ This pattern of performance is consistent with the hypothesis that EBA's oral production difficulties arise from damage at the level of retrieving stored, phonological representations of words for output (Caramazza \& Hillis, 1990). ${ }^{5}$

\section{Performance in the Production of Nouns and Verbs}

A striking feature of EBA's performance in naming and oral reiding was that her erroneous responses were mostly descriptions of the function of objects. In these descriptions she produced one or more correct verbs but few specific nouns. Thus, for example, in oral picture naming, the item SCISSORS elicited, "sewing machine, no, you use it when you're sewing, to cut," and RAZOR elicited, "I could use them when I'm shaving, a shaver"; and, the printed word tootbbrusb was read as "you use it to brush your teeth"; and sweater elicited, "something you wear when it's cold . . . dress." Interestingly, several of her erroneous responses in the reading task revealed that a specific phonological form might be available for use as a verb but not as a noun as illustrated by her reading of comb as, "It's used to comb your hair." Furthermore, she produced very few nouns; in naming 260 pictured objects, she produced only 118 nouns as responses, and only 64 of these were different nouns (for example, she said "dog" nine times and "pear" five times, although there was only one picture of a dog and one of a pear). To further investigate her difficulty with nouns, a number of studies compared her performance on nouns and verbs in various tasks.

Two sets of pictures, which reliably elicit the target name by normal subjects, were presented for oral naming. Both sets of nouns and verbs were also presented for reacling, and for word/picture matching, in the manner described for the previous set of pictures. Set 1 stimuli were colored pictures of 30 objects and 30 ac- tions (transitive verbs), with names matched in frequency and length. Results of naming of this set by patients HW and SJD were published in Caramazza and Hillis (1991); the same set was presented to EBA so that her performance could be contrasted to that of $\mathrm{HW}$ (who was more impaired for verbs than for nouns in oral production). Set 2 stimuli consisted of black and white drawings of 30 pure nouns and 30 pure verbs matched for base frequency (how often the single, unaffixed word occurs in the language) and length, and 30 pure verbs matched for cumulative frequency (how often the word occurs in any form in the language) and length to the nouns. Naming of these stimuli has been normed by Zingeser and Berndt (1988).

EBA's naming was accurate for a total of $12 \%(11 / 90)$ of the nouns and $72 \%(43 / 60)$ of the verbs $\left(\chi_{1}^{2}=55.2\right.$; $p \ll 0.0001$; Odd's Ratio $=18.2 ; 95 \%$ confidence interval $=7.8-42.3$ ). The discrepancy between nouns and verbs was highly significant for each pair of lists (Table 3 ). Her higher accuracy on nouns compared to verbs on Set 1 , which was equally as striking as for Set 2 , confirms the opposite dissociation with respect to word class from that of HW and SJD (Caramazza \& Hillis, 1991), obtained with the same stimuli.

EBA's erroneous responses in earlier tasks indicated that at times the form of the word was available for use as the verb form, but not the noun form. To confirm this speculation, EBA was presented with definitions of both the verb form and the noun form of 16 homonyms (for which the meaning of the noun form and of the verb form is not clearly related; e.g., pound, park, trip), and was asked to name the corresponding word. ${ }^{6}$ In one session half of the words were defined as the verb form and half were defined as the noun form. In a separate session, the alternate form was defined for each word. Two control subjects, matched in age and education to EBA, each correctly named $94 \%(15 / 16)$ of the words when defined as nouns and $81 \%(13 / 16)$ when defined as verbs.

In contrast to controls, EBA was significantly more impaired in naming the homonyms defined as nouns (19\% or $3 / 16$ correct) than in naming the same words defined as verbs $\left(75 \%\right.$ or $12 / 16$ correct; $\chi_{1}^{2}=10.2 ; p<$ 0.001 ). For example, she correctly named "shed" in response to "What dogs and cats do to get rid of their heavy coats," but not in response to "A small house-like structure, often a place to keep tools." Additional illustrations are given in Table 3 .

In another naming task EBA was asked to generate verbs in 10 categories (e.g., things you do outdoors) or nouns in 10 categories (e.g., things you use outdoors). The examiner accepted responses for as long as EBA was willing to give them. In this noun and verb generation task, EBA named a mean of $5.8(\mathrm{SD}=1.5)$ per category of verbs, and $0.6(\mathrm{SD}=1.6)$ per category of nouns. For example, she named nine "things you do with a baby" (e.g., "wash, feed, walk, watch"), but only one of "things you buy for a baby" ("diapers"), although she described 
Table 3. EBA's Performance on Nouns vs. Verbs in Various Tasks

\begin{tabular}{|c|c|c|}
\hline & Number (\%) Correct & Examples of Errors \\
\hline \multicolumn{3}{|l|}{ Oral Picture Naming } \\
\hline \multicolumn{3}{|l|}{ Set 1} \\
\hline Verbs & $21 / 30(70)$ & WADE $\rightarrow$ "seeing how high the water is" \\
\hline $\begin{array}{l}\text { Nouns matched in base } \\
\text { frequency }\end{array}$ & $3 / 30(10)$ & SOCK $\rightarrow$ "shoe"; BENCH $\rightarrow$ "to it on" \\
\hline Chi square & \multicolumn{2}{|l|}{$22.5(p \ll 0.0001)$} \\
\hline \multicolumn{3}{|l|}{ Set 2} \\
\hline Verbs & $22 / 30(73)$ & SHOOT $\rightarrow$ "gonna kill someone" \\
\hline $\begin{array}{l}\text { Nouns matched in base } \\
\text { frequency }\end{array}$ & $4 / 30(13)$ & GLASS $\rightarrow$ "drink"; BEE $\rightarrow$ "sting" \\
\hline Chi square & $22.0(p \ll 0.0001)$ & BADGE $\rightarrow$ "what cops wear" \\
\hline $\begin{array}{l}\text { Nouns matched in cumulative } \\
\text { frequency }\end{array}$ & $4 / 30(13)$ & $\begin{array}{l}\text { BELT } \rightarrow \text { "wear this"; OVEN } \rightarrow \text { "something you cook in . . } \\
\text { dishwasher" }\end{array}$ \\
\hline Chi square & \multicolumn{2}{|l|}{$22.0(p \ll 0.0001)$} \\
\hline \multicolumn{3}{|l|}{ Naming to defitions (homonyms) } \\
\hline Verb form & $12 / 16(75)$ & $\begin{array}{l}\text { "what you do when you roll a ball down an alley to hit } \\
\text { pins" (bowl) } \rightarrow \text { "bowl" }\end{array}$ \\
\hline Noun form & $3 / 16(19)$ & "a dish you use to eat soup or cereal" (bowl) $\rightarrow$ "a can" \\
\hline Chi square & \multicolumn{2}{|c|}{$10.2(p<0.001 ;$ Fisher's exact: $p<0.002)$} \\
\hline \multicolumn{3}{|l|}{ Generating names in categories } \\
\hline Verbs & Mean $=5.5$ & "methods of cooking" $\rightarrow$ "fry," "bake," "stew," "baste," "broil" \\
\hline Nouns & Mean $=0.5$ & "cooking utensils or appliances" $\rightarrow$ no response \\
\hline
\end{tabular}

others ("things to wash her"). These results are consistent with the observation that her spontaneous speech contains many more accurate verbs than nouns; e.g., a verbal description of a complex picture included six accurate names of actions and only two accurate names of objects (whereas patient HW's description of the same picture included more than three times as many names of objects as names of actions).

\section{Comment}

EBA's disproportionate difficulty in orally producing nouns relative to verbs was confirmed in several controlled experiments where she correctly produced only about $10 \%$ of nouns but over $70 \%$ of verbs (Tables 1 and 2 ), the reverse pattern of performance to that previously reported for patients HW and SJD (Caramazza \& Hillis, 1991). EBA's oral naming performance on Set 1 (70\% correct for verbs, $10 \%$ correct for nouns) showed the opposite effect of word class to that of HW on the same set of pictures $(20 \%$ correct for verbs, $53 \%$ correct for nouns). Both patients showed flawless performance in auditory comprehension tasks with both nouns and verbs. This double dissociation indicates that the contrast between nouns and verbs, which arises at the level of retrieving the phonological form of the words, cannot be explained by proposing that one word class is simply "more difficult" than the other word class. The fact that EBA showed a comparable advantage in retrieving the verb form even when it was phonologically identical to the noun form (in naming homonyms), just as $\mathrm{HW}$ showed a comparable advantage in retrieving the noun form in reading homonyms, indicates that word class information is important at this level of processing. Thesc results also provide additional evidence that EBA's impairment in oral production of nouns does not arise at the level of motor processes for articulating the word, since she adequately articulated the same sequence of phonemes in naming the verb form.

\section{Performance in the Recognition of Nouns and Verbs}

To evaluate access to the orthographic representations of verbs versus nouns for input, printed word/picturc verification was tested in the same manner as spoken word/picture verification (as described above) using the two sets of nouns and verbs tested in naming tasks. In this task with written input (that did not require verbal output), EBA also showed a striking dissociation be- 
Table 4. EBA's Performance on Tasks with Written Word lnput

\begin{tabular}{|c|c|c|}
\hline & Number $(\%)$ Correct & Examples of Errors \\
\hline \multicolumn{3}{|c|}{ Written word comprehension (word/picture verification) } \\
\hline \multicolumn{3}{|c|}{ Set 1} \\
\hline Verbs & $12 / 30(40)$ & $\begin{array}{l}\text { A picture of wading was accepted as a match for the } \\
\text { word row }\end{array}$ \\
\hline Nouns matched in base frequency & $30 / 30(100)$ & \\
\hline Chi square & $25.7(p \ll 0.0001)$ & \\
\hline \multicolumn{3}{|l|}{ Set 2} \\
\hline Verhs & $14 / 30(47)$ & $\begin{array}{l}\text { A picture of erasing was accepted as a match for the } \\
\text { word sharpen }\end{array}$ \\
\hline Nouns matched in base frequency & $30 / 30(100)$ & \\
\hline Chi square & $21.8(p \ll 0.0001)$ & \\
\hline Nouns matched in cum. frequency & $28 / 30(93)$ & $\begin{array}{l}\text { A picture of a trunk was accepted as a match for the } \\
\text { word sbarpen }\end{array}$ \\
\hline Chi square & $15.6(p<0.0001)$ & \\
\hline \multicolumn{3}{|l|}{ Written lexical decision } \\
\hline \multicolumn{3}{|l|}{ High frequency words } \\
\hline Verbs & $9 / 13(69)$ & decide $\rightarrow$ "is not a word" \\
\hline Nouns & $13 / 13(100)$ & \\
\hline \multicolumn{3}{|l|}{ Low frequency words } \\
\hline Verbs & $6 / 13(46)$ & deny $\rightarrow$ "is not a word" \\
\hline Nouns & $11 / 13(85)$ & sleeve $\rightarrow$ "is not a word" \\
\hline \multicolumn{3}{|l|}{ Nonwords } \\
\hline Pseudohomonyms & $32 / 34(94)$ & consept $\rightarrow$ "is a word" \\
\hline Nonhomonyms & $33 / 34(97)$ & $k i t t u l \rightarrow$ "is a word" \\
\hline
\end{tabular}

tween nouns and verbs, but in the opposite direction (Table 4). Using the same items that revealed an advantage for verbs over nouns with spoken output, EBA showed a striking advantage for nouns over verbs with written input. That is, although EBA's performance for nouns and verbs was $100 \%$ correct for spoken word comprehension, her accuracy in written word comprehension (combined sets) was only $43 \%$ for verbs but $98 \%$ for nouns $\left(\chi_{1}^{2}=58.5 ; p \ll 0.0001\right.$; Odd's Ratio $=57.5$; $95 \%$ confidence interval $=12.9-255)$. In this task she accepted $10 \%$ of the unrelated verbs, but none of the unrelated nouns as a match for the picture, and she rejected $33 \%$ of the correct verbs but none of the correct nouns as a match for the picture (e.g., given a picture of a boy sitting and the word sit, she said, "No, he's sitting. That word's not 'sit' is it?").

As another test of access to the input orthographic representations of verbs versus nouns, EBA was presented with written words and pseudowords, and was asked to state (under no time constraints) whether or not each stimulus was a correctly spelled English word. The list included nouns, verbs, and adjectives, counterbalanced for word frequency and length (in letters and phonemes), and pseudowords and functors matched in length to the other classes. EBA's accuracy in identifying words as real words was also significantly better for nouns $(24 / 26$ or $92 \%)$, compared to verbs $(15 / 26$ or $58 \%$; $\chi_{1}^{2}=15.2 ; p<0.0002$; Table 4). She accepted $75 \%$ of functors and $81 \%$ of adjectives. The difference between nouns and verbs could not be attributed to higher accuracy for concrete words; with a separate set of concrete and abstract, low- and high-frequency nouns mixed with pseudowords, EBA recognized an equal number (16/21) of the concrete nouns and of the abstract nouns (all errors were on low frequency words).

EBA's oral reading showed an advantage for verbs, but it was less striking than the advantage observed in oral naming: $9 \%(8 / 90)$ correct for reading nouns versus $33 \%$ $(20 / 60)$ correct for reading verbs $\left(\chi_{1}^{2}=14.2 ; p<0.0002\right.$; Odd's Ratio $=5.1 ; 95 \%$ confidence interval $=2.1-12.6$ ), as shown in Table 5 . In contrast to her reading errors on nouns, which were nearly always correct definitions or semantically related words like her oral naming responses, $60 \%$ of her attempts to read verbs were omissions or other indications that she could not access the meaning of the word. The advantage for verbs cannot be 
Table 5. EBA's Performance with Written Word Input and Verbal Output (Oral Reading)

\begin{tabular}{lcl}
\hline & Number $(\%)$ Correct & Examples of Errors \\
\hline $\begin{array}{l}\text { Set } 1 \\
\text { Verbs }\end{array}$ & $10 / 30(33)$ & $f r y \rightarrow$ "bake . . cook eggs" \\
Nouns matched in base frequency & $2 / 30(7)$ & boat $\rightarrow$ "we have one for boating" \\
$\quad 6.7(p<0.01)$ & \\
$\quad$ Chi square & $10 / 30(33)$ & sell $\rightarrow$ "I have no idea" \\
$\begin{array}{l}\text { Set } 2 \\
\text { Verbs }\end{array}$ & $3 / 30(10)$ & bee $\rightarrow$ "snake"; broom $\rightarrow$ "You use these when you sweep." \\
Nouns matched in base frequency & $4.8(p<0.03)$ & bed $\rightarrow$ "something you go to sleep in" \\
$\quad$ Chi square & $3 / 30(10)$ & pie $\rightarrow$ "to eat for dessert" \\
Nouns matched in cumulative & &
\end{tabular}

due to better reading of abstract words than concrete words, since she correctly read $4 / 21$ concrete nouns and $1 / 21$ abstract nouns, matched for length and frequency. Furthermore, some of her responses to abstract words were concrete words (e.g., degree was read as "diploma").

\section{Comment}

EBA's performance on written word/picture matching and word/nonword discrimination (lexical decision) tasks revealed the opposite effect of word class in reading comprehension (an advantage for nouns over verbs) compared to oral naming (an advantage for verbs over nouns). EBA's flawless performance on word/picture matching with both spoken nouns and spoken verbs indicates that neither effect can be attributed to a deficit at the level of obtaining the meaning of the word. That is, her intact comprehension with spoken words indicates that her errors in comprehension of written words occurred at the level of word recognition (accessing stored orthographic forms from written input) prior to accessing meaning. Further evidence that EBA's errors on verbs occurred at the level of accessing the orthographic forms of verbs for input was provided by her very poor performance in identifying written verbs (but not nouns) as real English words in lexical decision tasks (Table 4). Thus, it would seem that verbs were processed more accurately than nouns for spoken output and that nouns were processed more successfully than verbs for written input.

Oral reading, which involves both written input and spoken output, shows the combined effects of her input and output deficits. In fact, since EBA showed opposite effects of word class with written input (better for nouns) compared to spoken output (better for verbs), the two effects should, to some extent, "cancel each other out" in oral reading. This conclusion can be drawn in the case of EBA because, as discussed in the cast report (see below), she is unable to read by "sounding out" words. In the absence of functional sublexical mechanisms for converting print to sound, she should be able to read aloud only by accessing stored, orthographic forms for input and stored phonological forms for output. Since we have argued that she has no damage to the lexical-semantic component, her oral reading ought to reflect the "sum" of her deficits at the levels of input and output forms. That is, we should be able to predict her oral reading performance for both verbs and nouns from the results presented so far regarding her processing of phonological forms for output (measured by naming accuracy) and results regarding her processing of orthographic forms for input (measured by printed word/picture verification) with the same items. Thus, in response to written verbs we tested, she should correctly read about $72 \%$ (her accuracy in naming verbs) of the $43 \%$ she recognizes, or $31 \%$. In response to written nouns, she should correctly read aloud about $12 \%$ of the $98 \%$ she recognizes, or $12 \%$. The results were very close to these predictions: EBA read correctly $33 \%$ of the verbs and $9 \%$ of the nouns that were tested in naming and comprehension tasks (Table 5).

\section{DISCUSSION}

The main results from the above studies-summarized in Figure 1-are as follows: (1) EBA is significantly morc impaired in producing nouns than verbs in all speech tasks; and (2) she is selectively impaired in recognizing the written form of verbs but not nouns. This combination of results has important implications for theories of the organization of Iexical knowledge in language use and for the representation of this knowledge in the brain.

First, the fact that EBA is more impaired in the oral production of nouns than verbs provides a crucial con- 
Figure 1. A summary of EBA's performance on verbs compared to nouns on tasks with different input and output modalities.

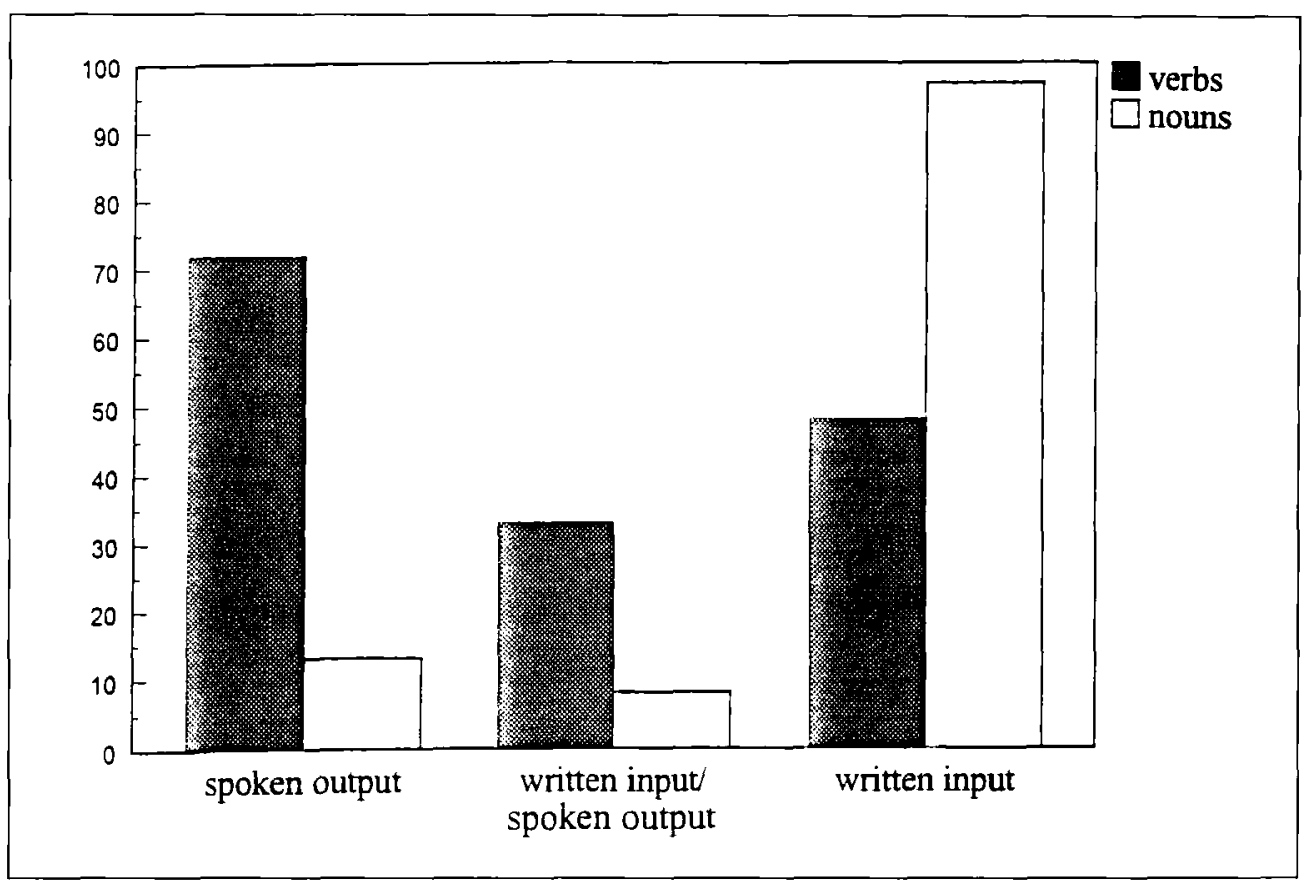

trast to the previously reported opposite dissociation between nouns and verbs in all speech tasks for patient HW (Caramazza \& Hillis, 1991). This double dissociation, using the same stimuli for the two patients, suggests that the reported difference between nouns and verbs cannot be accounted for by general differences in degree of difficulty between the two word classes. These facts, together with the observation that EBA, as well as HW, showed flawless comprehension of both nouns and verbs in the auditory modality, suggest that the selective difficulty in the oral production of nouns for EBA and of verbs for $\mathrm{HW}$ results from a deficit at the level of retrieval of the pronunciation of words-the phonological output lexicon. One implication of the foregoing is that lexical phonological knowledge for nouns and verbs is represented independently in the brain.

Second, the fact that EBA is severely impaired in recognizing and comprehending written verbs despite normal performance in recognizing and comprehending spoken verbs and spoken and written nouns suggests that she has an impairment at the level of access to stored orthographic forms-the orthographic input lexicon. The advantage for nouns over verbs in printed word recognition tasks could not be attributed to the fact that nouns are more concrete, since her performance with abstract and concrete nouns was identical. One implication of this result is that lexical ortbograpbic knowledge, as well as lexical phonological knowledge, for nouns and verbs is represented independently in the brain.

The reported results can be accounted for by proposing that EBA has contrasting grammatical category-specific deficits at the level of accessing stored orthographic representations of words (for input) and at the level of accessing stored phonological representations of words (for output). Her oral reading performance reflects both her deficit in written word recognition and her deficit in phonological output. The quality of EBA's errors in oral reading either reflected the written word recognition deficit (mostly in reading verbs) in which case she responded, "I have no idea" or the equivalent, or reflected her phonological output deficit in which case she produced a word or description semantically related to the target (e.g., book $\rightarrow$ "read"). She never produced words that were only visually related or phonologically related to the target in oral reading. Her production of semantic but not visual/phonological errors in reading was also observed when she was asked to read the concrete and abstract word stimuli presented in the lexical decision task. To illustrate, she read borror as "frightened" and moment as "second." These results are inconsistent with models of reading that predict a necessary cooccurrence of visual errors and semantic errors in reading abstract words (Coltheart, 1980) or in reading all words (Plaut \& Shallice, 1993).

In summary, the contrasting patterns of grammatical category-specific impairments in separate modalities of input and output within the same patient, together with previous reports of the opposite grammatical categoryspecific impairment documented in each modality of output, provide strong evidence for the hypothesis that knowledge of orthographic and phonological forms is organized by grammatical category, and that separate brain structures subserve the processing of nouns and verbs for written and spoken language (Caramazza et al., 1994; Damasio \& Tranel, 1993; Hillis \& Caramazza, 1995). Damasio and Tranel (1993) make a more specific anatomical claim based on three reported cases (along with another seven cases they have studied, which are report- 
edly consistent with the claim). These authors propose that nouns are represented in the left anterior and middle temporal regions and that verbs are represented in the left frontal region. Additional evidence favoring this general anatomical organization of grammatical categories is that patients with fluent aphasia falling in the clinical categories of "Wernike's aphasia" and "anomic aphasia," who typically have more posterior lesions, also tend to have more difficulty naming nouns than verbs. In contrast, patients whose speech is nonfluent and who fall into the category of "Broca's aphasia" typically have frontal lesions and often have more difficulty naming verbs than nouns (Miceli, Silveri, Nocentini, \& Caramazza, 1988). Although exceptions to the common cooccurrence between nonfluent aphasia and difficulty in naming verbs, as well as between fluent aphasia and difficulty naming nouns have been reported (Kremin, in press; Caramazza \& Hillis, 1991), these cases were not studied in such a way as to test any hypothesis about the anatomical organization of nouns and verbs.

EBA's dual impairments in naming nouns and in recognizing written verbs, following strokes that involved both the left frontal and left temporal regions (Fig. 2), are not inconsistent with the proposal of Damasio and Tranel. That is, her trouble recognizing verbs might be due to her left frontal lesion and her trouble with nouns might be due to her left temporal lesion. However, this proposal alone does not capture the depth of the patterns of dissociations seen in EBA's performance, since her deficit involving nouns was restricted to verbal output and her deficit involving verbs was restricted to written input. Likewise, two of the patients reported by Damasio and Tranel (AN-1033 and KJ-1360) had a word class-specific difficulty only in spoken and written output, whereas the other patient (Boswell) had word-class specific difficulty in comprehension as well as spoken and written output. Together, these cases indicate that lexical output representations of nouns are subserved by neuroanatomical mechanisms (purportedly in the left temporal region), which are separate from the neuroanatomical mechanisms that subserve the semantic representations of nouns (also purportedly in the left temporal region), and which are separate from the neuroanatomical mechanisms that subserve the lexical representation of nouns (purportedly in the left frontal region). The performance of EBA suggests an even finer "division of labor," in which separate neural mechanisms are devoted to orthographic, phonological, and semantic representations for a given grammatical class. Unfortunately, the relatively large lesions produced by strokes have not provided evidence for more detailed hypotheses about the anatomical correlates of orthographic versus phonological versus semantic representations of nouns and verbs. Nevertheless, along with a number of recent reports that brain damage can result in categoryspecific deficits that arise at the level of the meaning of words and other reports of category-specific deficits at the level of orthographic and phonological forms of words, the present results provide testimony for a remarkably fine-grained organization of lexical knowledge in the brain.

\section{METHOD}

\section{Subject}

EBA is a premorbidly right-handed female high school graduate, who retired from an administrative job in the county government at the age of 57,7 years before this investigation, when she suffered an ischemic stroke (in 1985). Prior to that time, her medical history was significant only for hypertension and smoking 2 packs of cigarettes per day. The stroke involved the left frontal lobe and basal ganglia (see CT in Fig. 2, top), and resulted

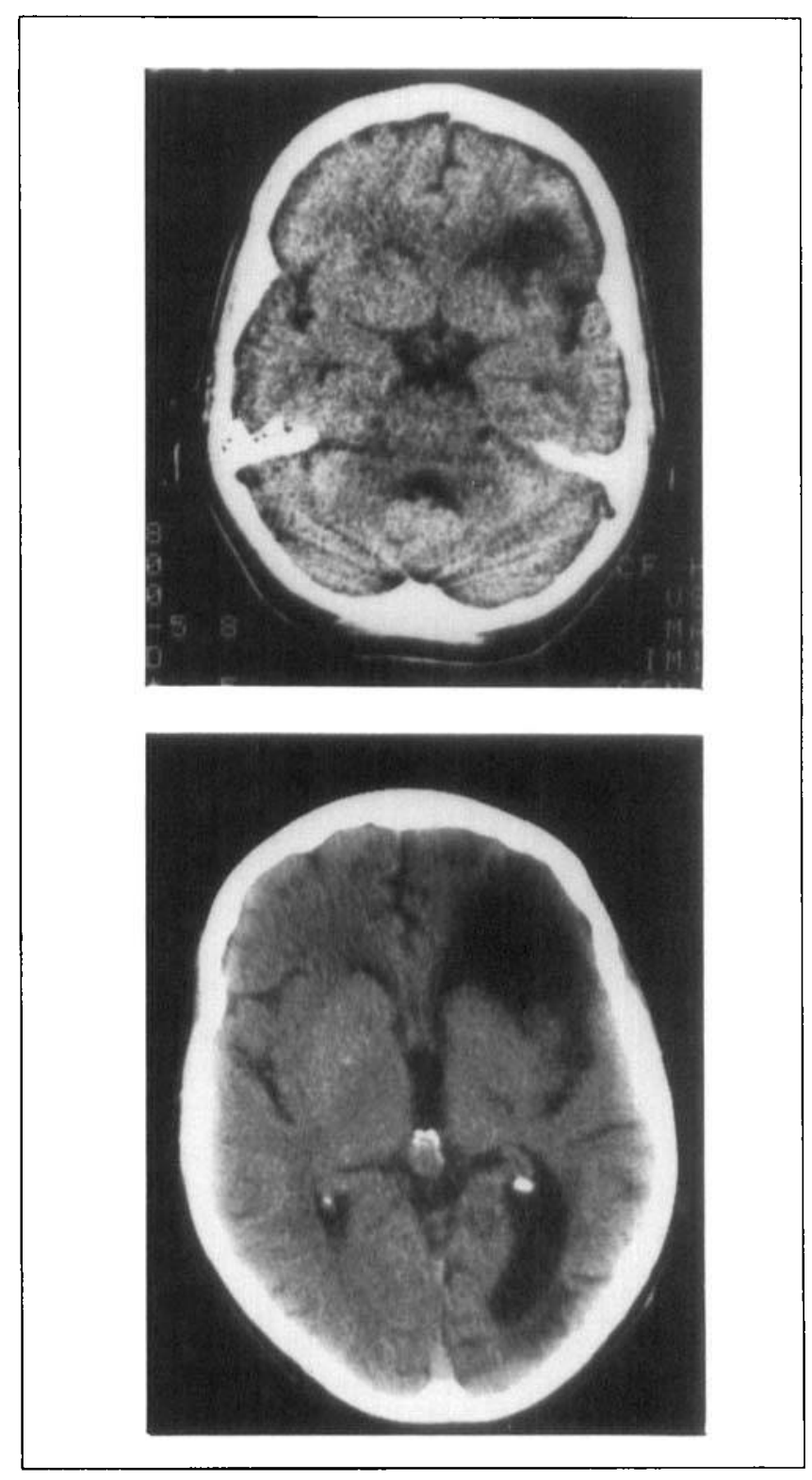

Figure 2. CT scans of EBA's brain after the first stroke (top) and 4 years after her second stroke (bottom). She had no clinical significant neurological event after the second stroke. 
in right hemiparesis involving the arm, leg, and the lower face; mild word-finding difficulty; and a severe spelling impairment. Despite the apparent involvement of "Broca's area" (according to the CT), her speech was fluent and grammatical. Her scores from the Western Aphasia Battery 2 months poststroke were reportedly consistent with "anomic aphasia," although she correctly named 58/60 objects. On the same test her score for reading was $96.5 / 100$, and her score for writing was $40 / 100$. We do not have access to further details of that testing. It is notable that the Western Aphasia Battery does not test recognition of written verbs, except in the context of sentences and paragraphs.

A carotid angiogram in 1985 revealed complete occlusion of the left internal carotid. It was felt that surgery was not indicated, and so she was managed on daily Coumadin. She did well for 5 years except for persisting right spastic hemiparesis and spelling difficulty. She had recovered all other language abilities according to her own report and that of her family. She was independent in walking and in all activities of daily living

In 1990, EBA had an additional stroke. No changes were seen on the initial CT the day of her stroke, but a recent $\mathrm{CT}$ showed both old strokes; the second involved a "watershed" area in the left frontotemporoparietal region. The CT scans in Figure 2 show the first stroke involving the left frontal area only (top) and the second stroke involving at least the left temporal region as well as possible extension of the old left frontal lesion (top and bottom). The only changes in her status due to the second stroke that were noted by EBA and her family were a sudden inability to read and increased difficulty in retrieving words in speech. Other functional skills and mobility were not affected.

A neurological examination following her second stroke was most remarkable for her old right spastic hemiparesis (greater in the arm than the leg) and "expressive aphasia." Her cranial nerve examination was normal except for a very mild right central facial palsy. Visual fields were full. Deep tendon reflexes were $2+$ on the left. $3+$ in the right leg, and could not be elicited (due to spasticity) in the right arm. A right Babinski sign and Hoffman's sign were elicited. Sensation was subjectively depressed for pinprick and temperature in the right arm and leg, but was intact for vibration and proprioception.

A speech pathology evaluation, which included administration of the Boston Diagnostic Aphasia Examination (Goodglass \& Kaplan, 1972), a few days after her second stroke yielded the clinical diagnosis of "anomic aphasia." Her aphasia was characterized by a profound impairment $(0 \%$ correct) in naming objects and in oral reading, despite fluent, grammatical, and well-articulated speech that contained frequent circumlocutions and semantic paraphasias. She showed relatively spared ability to match printed words to pictures of objects. When the current study began, EBA had persisting right hemipare- sis; but her cranial nerve examination, diadochokinesis, and visual fields were normal. She was independent in all activities of daily living, but did not attempt to drive. She showed only a slight improvement in naming and reading (described above). She remained profoundly unable to produce a single correct response in attempts to read aloud pseudowords (e.g., ribe), including those homophonic to a real word (e.g., floot). In fact, EBA was completely unable to provide a phonemic rendition of individual printed letters, syllables, or unfamiliar words. She was also impaired in pointing to one of two pseudowords to match the examiner's spoken pronunciation (e.g., she pointed to dree rather than buke to match /bjuk/, rhyming with "puke"). Together, these results indicate profound impairment of sublexical mechanisms for "sounding out" printed words (orthography to phonology conversion mechanisms). Her performance was flawless in tests of word and sentence repetition and of comprehension of spoken sentences (including grammatically complex sentences); her score on the Peabody Picture Vocabulary Test (Dunn \& Dunn, 1981) was in the normal range.

\section{Procedure}

The subject was tested in her own home, for 2 hour sessions, with rest breaks as requested. In all tasks the stimuli were presented without time constraints. All of the patient's responses were recorded, but only her final response was scored. Interjudge reliability in scoring written and oral (naming and reading) responses, measured during one session, was $100 \%$.

\section{Acknowledments}

The authors are grateful to EBA for her tireless and goodnatured participation in this study. We also wish to thank an anonymous reviewer for helpful conments on an earlier draft. The research supported in this paper was supported by NIH Grant (NINCD) ROI 19330 to Dartmouth College.

Reprint requests should be sent to Alfonso Caramazza, Department of Psychology, William James Hall, Harvard University, Cambridge, MA 02138.

\section{Notes}

1. Throughout this report a word in CAPITAL letters designates a picture stimulus; a word in italics designates a written word stimulus or response, and a word in quotes designates a spoken stimulus or response. The word preceding an arrow is a stinuulus; a word following an arrow is a response.

2. Following each omission in oral reading, EBA was given the names of 10 categories (e.g., furniture, vegetables), and was asked to identify the category to which the stimulus belongs. She was accurate (but often not confident) in this decision on 24/25 trials. After selecting the category, she often went on to give a more accurate reading response. For example, after identifying barn as a building she said, "I see them in the 
country, a pretty big building; they put animals in it." However, these prompted responses were not scored.

3. Written naming was not tested extensively (at the patient's request), but EBA sometimes spontaneously wrote the correct name, or part of the correct name, when she could not verbally produce it. For example, in response to a pictured banana she said, "something you eat, a cantaloupe," but she wrote banana. In response to a picture of a potato, she said, "cake, pie, cookies, bread, butter, no . . ." and she wrote pototo. (She then added, "That's not right, but our Vice President can't spell it either.") However, her spelling to dictation and her written naming of both nouns and verbs were severely impaired. As often as she wrote words that she could not say, she spoke words that she could not spell in naming tasks, with the result that there was no difference in the accuracy rates for oral and written naming of the same objects (see Note 6).

4. The facts that EBA's reading was no better than her oral naming and that reading errors were not phonologically related to the stimulus indicate that EBA had an impairment to sublexical mechanisms for converting print to sound in addition to damage at the level of retrieving phonological representations of words for output. Further support from this hypothesis was provided by her inability to read or recognize pseudowords (see the case report).

5. The present results do not allow us to be more specific about the nature of EBA's impairment at the level of accessing phonological representations for output. Although many authors have distinguished between deficits of storage and access procedures at the level of the phonological output lexicon, it has been forcefully argued that these two forms of deficit are empirically indistinguishable in current theoretical formulations (Rapp \& Caramazza, 1993). Furthermore, although several models of normal speech production specify multiple stages in the retrieval of lexical-phonological forms from semantic representations (e.g., Butterworth, 1983; Garrett, 1992), the present analyses were not intended to localize EBA's deficit to one or the other of these procedures. Instead, analyses were undertaken to show that whatever sort of access procedures or representations are impaired in EBA, the neural mechanisms supporting them are distinct for nouns versus verbs.

6. EBA was not asked to read homonyms in the context of sentences including the noun or the verb form, as were SJD and $\mathrm{HW}$, because she had an independent reading deficit, described below.

7. EBA was impaired on tasks of written output as well as written input. However, she showed neither the advantage for nouns found with written input nor the advantage for verbs found with spoken input. Her spelling to dictation for the items used in the previous tasks was $10 \%(3 / 30)$ correct for the verbs and $8 \%(5 / 60)$ correct for the nouns; written naming was $10 \%$ correct for both nouns and verbs. She made many partial responses (e.g., pie $\rightarrow$ "does it start with "p"?"; moon $\rightarrow$ "does it have 2 of these $-0 o-$ in it?"; dog $\rightarrow g$ ). One possible account of these partial responses is that they reflect intact access to a representation of the spelling of the word followed by a deficit in more peripheral processes, such as selecting a specific letter shape (or name) or "holding" the sequence of letter shapes while she executes motor sequences for spelling. An alternative account is that her partial responses indicated "partial access" to a lexical orthographic representation for output.

\section{REFERENCES}

Basso, A., Capitani, E., \& Laiacona, M. (1988). Progressive language impairment without dementia: A case with isolated category-specific naming defect. Journal of Neurology, Neurosurgery, and Psychiatry, 51, 1201-1207.
Baxter, D. M., \& Warrington, E. K. (1985). Category-specific phonological dysgraphia. Neuropsycbologia, 23, 653-606. Butterworth, B. (1983). Lexical representation. In B. Butterworth (Ed.), Language production (Vol. 2). London: Academic Press.

Caramazza, A. (1988). Some aspects of language processing revealed through the analysis of acquired aphasia: The lexical system. Annual Review of Neuroscience, 11, 395-421

Caramazza, A., \& Hillis, A. E. (1990). Where do semantic errors come from? Cortex, 26, 95-122.

Caramazza, A., \& Hillis, A. E. (1991). Lexical organization of nouns and verbs in the brain. Nature (London) 349, 788790 .

Caramazza, A., Hillis, A. E., Leek, E., \& Miozzo, M. (1994). The organization of lexical knowledge in the brain: Evidence from category- and modality-specific deficits. $\ln \mathrm{L}$. Hirschfeld, \& S. Gelman (Eds.), Domain specificity' in cognition and culture. (pp. 68-84) Cambridge: Cambridge University Press.

Coltheart, M. (1980). Reading, phonological recoding and deep dyslexia. In M. Coltheart, K. E. Patterson, \& J. C. Mar shall (Eds.), Deep dyslexia. (pp. 146-159) London: Routledge and Kegan Paul.

Damasio, A. R. (1990). Category-related recognition defects as a clue to the neural substrates of knowledge. Trends in Neuroscience, 13, 95-98.

Damasio, A. R., \& Tranel, D. (1993) Nouns and verbs are retrieved with differently distributed neural systems. Proceedings of the National Academy of Sciences of the United States of America, 90, 4957-4960.

Dunn, L. M., \& Dunn, L. M. (1981). Peabody Picture Vocabulary Test-revised. Circle Pines, MN: American Guidance Service.

Ellis, A. W., Miller, D., \& Sin, G. (1983). Wernicke's aphasia and normal language processing: A.case study in cognitive neuropsychology. Cognition, 15, 111-114.

Ellis, A. W., \& Young, A. (1988). Human cognitive neuropsycbology. London: Lawrence Eribaum.

Farah, M., Hammond, K. H., Metha, Z., \& Ratcliff, G. (1989). Category-specificity and modality-specificity in semantic memory. Neuropsycbologia, 13, 181-190.

(iarrett, M. F. (1992). Disorders of lexical selection. Coynition, 42, 143-180.

Goodglass, H., \& Kaplan, E. (1972). The Boston diagnostic aphasia examination. Philadelphia, PA: Lea, \& Febiger.

Goodglass, H., Klein, B., Carey, P., \& Jones, K. J. (1966). Specific semantic word categories in aphasia. Cortex, 2, 74-89

Hart, J., Berndt, R., \& Caramazza, A. (1985). Category-specific naming deficit following cerebral infarction. Nature ( $\mathrm{Lon}$ don), 3/6, 338.

Hart, J., \& Gordon, B. (1993). Neural subsystems for object knowledge. Nature (London), 359, 60-64.

Hillis, A., \& Caramazza, A. (1991). Category specific naming and comprehension impairment: $A$ double dissociation. Brain 114, 2081-2094.

Hillis, A. E., \& Caramazza, A. (1995). Category- and modality specific deficits in lexical processing. Proceedings of the 9th International Symposium of the Tokyo Metropolitan Institute for Neuroscience (Exerpta Medica International Congress series). In press.

Hillis, A., Rapp, B., Romani, C., \& Caramazza, A. (1990). Selective impairments of semantics in lexical processing. Cosmitive Neuropsychology 7, 191-243.

Hinton, G. E., \& Shallice, T. (1991). Lesioning an attractor network: Investigations of acquired dyslexia. Psycbological Review, 98, 74-95.

Hooper, C. (1991). To be or not two bees: Verbs, nouns, and the brain. The Journal of NIH Research, 3, 49-54. 
Kremin, H. (1995). Apropos the mental lexicon: The naming of nouns and verbs. In F. J. Stachowiak, R. De Bleser, G. Deloche, R. Kaschel, H. Kremin, P. North, L. Pizzamiglio, I. Robertson, \& B. Wilson (Eds.), Developments in the assessment and rebabilitation of brain damaged patients - Perspectives from a European concerted action. Tubingen: Narr Verlag. In press.

McCarthy, R. A., \& Warrington, E. K. (1985). Category specificity in an agrammatic patient: The relative impairment of verb retrieval and comprehension. Neuropsychologia, 23, 709-723.

McCarthy, R. A., \& Warrington, E. K. (1989). Evidence for modality-specific meaning systems in the brain. Nature (London), 3.34, 428-430.

Miceli, (i., Silveri, M. C., Nocentini, U., \& Caramazza, A. (1988) Patterns of dissociation in comprehension and production of nouns and verbs. Aphasiology, 2, 351-358.

Miceli, (i., Silveri, M. C., Villa, G., \& Caramazza, A. (1984). On the hasis of agrammatics' difficulty in producing main verbs Cortex, 20, 217-220.

Nielson. J. M. (1936). Agnosia, apraxia, and apbasia: Their value in cerebral localization. New York: Paui B. Hoeber.

Patterson, K. E., \& Morton, J. (1985). From orthography to phonology: An attempt at an old interpretation. In K. E. Patterson, M. Coltheart, \& J. C. Marshall (Eds.), Surface dyslexia. (pp. 335-360). London: Erlbaum.

Plaut, D. \& Shallice, T. (1993). Deep dyslexia: A case study of connectionist neuropsychology. Cognitive Neuropsychology, 10, 377-500.

Rapp, B., \& Caramazza, A. (1993). On the distinction between deficits of access and deficits of storage: A question of theory. Cognitive Neuropsychology, 10, 113-142.

Roeltgen. D. P., Rothi, L., \& Heilman, K. M. (1986). Linguistic semantic agraphia: A dissociation of the lexical spelling system from semantics. Brain. \& Lanvuage, 27, 257-280.

Sartori, G., \& Job, R. (1988). The oyster with four legs: A neuropsychological study on the interaction of visual and semantic information. Cognitive Neuropsychology 5, 105132.

Silveri, M. C., \& Gainotti, G. (1988). Interaction between vision and language in category-specific semantic impairment. Cognitive Neurobsycbology 5, 677-709.

Snodgrass, J. G., \& Vanderwart, M. (1980). A standardised set of 260 pictures: Norms for name agreement, image agreement, familiarity and visual complexity. Journal of Experimental Psycbology: Human Learning and Memory, 6, 174-214.

Tranel, D., Damasio, A. R., \& Damasio, H. (1988). Intact recognition of facial expression, gender, and age in patients with impaired recognition of face identity. Neurology, 38 , 690-696.

Warrington, E. K. (1981). Neuropsychological studies of verbal semantic systems. Pbilosophical Transactions of the Royal Society of London, B295, 411-423.

Warrington, E. K., \& McCarthy, R. A. (1983). Category specific access dysphasia. Brain, 106, 859-878.

Warrington, E. K., \& McCarthy, R. A. (1987). Categories of knowledge: Further fractionations and an attempted explanation. Brain, $110,1273-1296$.

Warrington, E. K., \& Shallice, T., (1984). Category specific semantic impairments. Brain, 107, 829-853.

Zingeser, L. B., \& Berndt, R. S. (1988). Grammatical class and context effects in a case of pure anomia: Implications for models of language production. Cognitive Neuropsychology 5, 473-516. 


\section{This article has been cited by:}

1. F. Pulvermuller, Y. Shtyrov. 2008. Spatiotemporal Signatures of Large-Scale Synfire Chains for Speech Processing as Revealed by MEG. Cerebral Cortex 19:1, 79-88. [CrossRef]

2. Marinella Cappelletti, Felipe Fregni, Kevin Shapiro, Alvaro Pascual-Leone, Alfonso Caramazza. 2008. Processing Nouns and Verbs in the Left Frontal Cortex: A Transcranial Magnetic Stimulation StudyProcessing Nouns and Verbs in the Left Frontal Cortex: A Transcranial Magnetic Stimulation Study. Journal of Cognitive Neuroscience 20:4, 707-720. [Abstract] [PDF] [PDF Plus]

3. MAUREEN DENNIS, DERRYN JEWELL, ROSS HETHERINGTON, CHRISTINE BURTON, MICHAEL E. BRANDT, SUSAN E. BLASER, JACK M. FLETCHER. 2008. Verb generation in children with spina bifida. Journal of the International Neuropsychological Society 14:02. . [CrossRef]

4. Dafna Palti, Michal Ben Shachar, Talma Hendler, Uri Hadar. 2007. Neural correlates of semantic and morphological processing of Hebrew nouns and verbs. Human Brain Mapping 28:4, 303-314. [CrossRef]

5. Stefan Heim, Kai Alter, Angela D. Friederici. 2006. A dual-route account for access to grammatical gender: evidence from functional MRI. Anatomy and Embryology 210:5-6, 473-483. [CrossRef]

6. Daniel Tranel, Thomas J. Grabowski, Jill Lyon, Hanna Damasio . 2005. Naming the Same Entities from Visual or from Auditory Stimulation Engages Similar Regions of Left Inferotemporal CorticesNaming the Same Entities from Visual or from Auditory Stimulation Engages Similar Regions of Left Inferotemporal Cortices. Journal of Cognitive Neuroscience 17:8, $1293-1305$. [Abstract] [PDF] [PDF Plus]

7. REZA KORMI-NOURI, LARS-GORAN NILSSON, NOBUO OHTA. 2005. The novelty effect: Support for the Novelty-Encoding Hypothesis. Scandinavian Journal of Psychology 46:2, 133-143. [CrossRef]

8. Argye E. Hillis, Sangjin Oh, Lynda Ken. 2004. Deterioration of naming nouns versus verbs in primary progressive aphasia. Annals of Neurology 55:2, 268-275. [CrossRef]

9. Argye E. Hillis , Elizabeth Tuffiash, Alfonso Caramazza . 2002. Modality-Specific Deterioration in Naming Verbs in Nonfluent Primary Progressive AphasiaModality-Specific Deterioration in Naming Verbs in Nonfluent Primary Progressive Aphasia. Journal of Cognitive Neuroscience 14:7, 1099-1108. [Abstract] [PDF] [PDF Plus]

10. Marion L. Kellenbach , Albertus A. Wijers, Marjolijn Hovius , Juul Mulder, Gijsbertus Mulder . 2002. Neural Differentiation of Lexico-Syntactic Categories or Semantic Features? Event-Related Potential Evidence for BothNeural Differentiation of Lexico-Syntactic Categories or Semantic Features? Event-Related Potential Evidence for Both. Journal of Cognitive Neuroscience 14:4, 561-577. [Abstract] [PDF] [PDF Plus]

11. Gabriele Miceli , Patrizia Turriziani , Carlo Caltagirone, Rita Capasso, Francesco Tomaiuolo , Alfonso Caramazza . 2002. The Neural Correlates of Grammatical Gender: An fMRI InvestigationThe Neural Correlates of Grammatical Gender: An fMRI Investigation. Journal of Cognitive Neuroscience 14:4, 618-628. [Abstract] [PDF] [PDF Plus]

12. Guila Glosser, Nancy Donofrio. 2001. Differences between nouns and verbs after anterior temporal lobectomy. Neuropsychology 15:1, 39-47. [CrossRef]

13. FRIEDEMANN PULVERMÜLLER. 1996. Hebb's concept of cell assemblies an the psychophysiology of word processing. Psychophysiology 33:4, 317-333. [CrossRef] 